\title{
Transcultural Nursing: Is it just the Knowledge of Culture?
}

\author{
Mariela Aguayo-González* \\ Department of Nursing, Faculty of Medicine Universitat Autónoma de Barcelona, Spain
}

\section{SHORT COMMUNICATION}

Nursing discipline is a very broad science that allows the healthy or sick person to be approached from multiple approaches. In addition, it is imperative of the profession to consider ethics, bioethics and the humanization of care in nursing practice.

However, to comply with all these fundamental elements of the profession, it is necessary to take care of the person from a cross-cultural approach, which will involve providing care from the understanding of the beliefs and customs of the people we serve. That is, to deepen personal values, individual conceptions and perspectives of the disease health process from the individual and unique vision that people possess. You cannot talk about ethics, bioethics or humanized care if we do not consider nurse transculturality. We can understand this process as an approach to the true meaning and meaning of health and illness from the perspective of the person we care for.

This care requires a simultaneous effort by the person who requires care and the agent that provides it, but the greatest effort will have to be made by any nurse or health agent, who has a faceto-face relationship with the person attended. For this person, and only by consulting and submitting to health care, is in a condition of vulnerability that makes them fragile and dispossessed of their cultural roots. Hence the importance of stopping to think about this phenomenon, and try to make an effort of understanding, understanding and empathy of the action of caring from the nurse transculturality.
The importance of including cultural competencies in nursing curricula has been talked about for some time, and cultural care is also discussed. The bibliography to the respect, indicates that it is essential to ensure that students have the knowledge, attitudes, and skills that allow them to work effectively with patients and their families, as well as with other members of communities and the health care medical community [1]. But how can we ensure these competencies in Nursing Education? We cannot safeguard the fulfillment of these competences, just because they are included in the curricula. It is necessary to include in the theoretical but also practical training, teaching models that tend towards a cultural immersion of health agents. The only way to understand the true essence of the sense of the process of health and illness for the caregiver with all that this implies; Adherence to treatment, health beliefs, religion, etc., will be to live this process from a much more experiential way and close to the real needs of the person. In this global and technological world, the true nurse presence with all the virtues that this means, must be and be in a direct relationship and from the culture of the person. It is for all the above that the only way to protect a humanized, ethical and personal nurse practice will be through a nursing practice from a cross-cultural perspective.

\section{REFERENCES}

1. Davidhizar R, Giger JN (2001) Teaching culture within nursing curriculum using the Giger-Davidhizar model of transcultural nursing assessment. J Nurs Educ 40(6): 282-284.

Quick Response Code: $\quad$ Address for correspondence: Mariela Aguayo-González, Department of Nursing, Faculty of Medicine Universitat Autónoma de Barcelona, Spain

Received: November 20, 2019 Published: November 25, 2019

How to cite this article: Mariela Aguayo-González. Transcultural Nursing: Is it just the Knowledge of Culture?. 2019 - 1(3) OAJBS.ID.000116. DOI: 10.38125/OAJBS.000116 